\title{
Rethinking the Socio-economic Value of Big Science: Lessons from the FCC Study
}

\author{
Johannes Gutleber
}

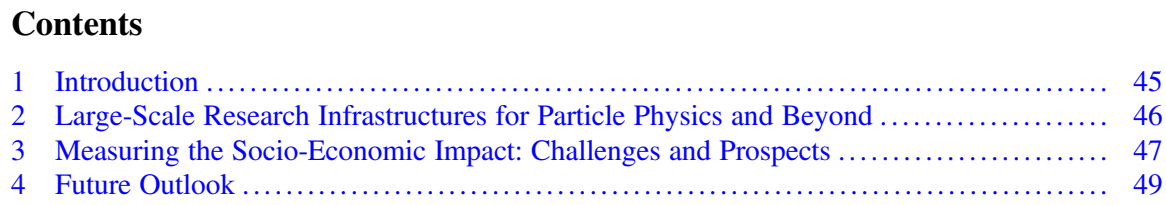

\section{Introduction}

Investing in fundamental research is often considered a risky venture. The associated costs for designing, developing and building new scientific instruments, the long timelines for the construction and operation of these facilities and the sophistication of the enabling technologies - often calling for further R\&D investments to meet the market needs - are among the fear-factors that enter into the debate around the investment in fundamental research.

This is also the case for High-Energy Physics. To study nature with higher precision and to understand the fundamental building blocks of our Universe, we need high-performance particle colliders. The construction and operation of the LHC serves as an example. Yet it often goes unnoticed that these large-scale research instruments can also offer positive returns for economy and society as well as many opportunities for industry and enable co-innovation through international collaboration among academic centres and laboratories. We note a similar picture in other areas of fundamental research like astrophysics or the emerging field of gravitational waves astronomy that also call for large-scale research infrastructures and significant public investments.

In the course of the twentieth century, we have witnessed how big research facilities generate a focal point for collaboration among a multitude of actors from

\footnotetext{
J. Gutleber $(\bowtie)$

Directorate for Accelerators \& Technology, CERN, Geneva, Switzerland e-mail: Johannes.gutleber@cern.ch 
academia and industry. Benefits stemming from large-scale facilities, often go beyond the pure scientific knowledge we gain from them about nature. They act as hubs of innovation and technological and scientific collaboration, alongside their core scientific missions. They regularly enable synergies among the producers of knowledge and the industrial partners or innovators that turn out close to market products. History has shown that big scientific facilities consistently yield surprises that in turn are converted into products while sometimes giving birth to whole new industry sectors.

Science and technology underpin much of the advance of human welfare and the long-term progress of our civilization. This is reflected in an extraordinary growth in public investment in science. At the same time we see a rising demand to demonstrate the societal return from these investments. The rising interest on the type of benefits that emerge and how they can be maximized and redistributed to society gives rise to a new field of interdisciplinary research bringing together economists, social scientists, historians and philosophers of science and policy makers.

\section{Large-Scale Research Infrastructures for Particle Physics and Beyond}

Let me focus on the field that I have been working for the past decades, namely accelerator-based research infrastructures. Today, we are at a critical moment for fundamental physics following the discovery of the Higgs and the first observation of gravitational waves, both opening new windows in our quest to understand the Universe. At the same time we are entering a critical stage for shaping the science policies that can tackle the scientific challenges of the twenty-first century. In the European landscape we witness the ongoing discussions about an ambitious postH2020 framework programme for Research \& Innovation, the establishment of the European Innovation Council and the adoption of a mission-oriented policy to bridge the gap between the research cloud and market needs to name but a few of the ongoing processes. We also observe similar debates and transitions taking place at a global scale with new countries raising their public investments in big research infrastructures.

In fact, there is a rising consensus that research infrastructures have a broader return for society beyond their core scientific mission. This is why in my view we should not give up on quantifying and furthermore strive to maximize the socioeconomic impact generated from Big Science facilities.

This point bring me to the second question that I would like to touch during this short presentation; namely how much basic research is needed to go beyond 'new fundamental knowledge' and achieve what one calls 'usefulness'? Can we afford as a society a continuous investment in curiosity-driven research that doesn't promise precise and immediate applicable results? These are questions that more and more inform the public debate and remind us of the political and societal importance of science while calling for continuous efforts to communicate and disseminate our 
results. As we are moving towards a new science-oriented economy of knowledge and innovation we need to revisit the role of RI's and the ecosystem that they support. This means that we need tools and more data that will allow design RIs in a way that could maximize their socio-economic impact and policy-makers to arrive at more informed decisions.

Designing a global-scale project, like the Future Circular Collider for a post-LHC collider-based infrastructure unavoidably triggers discussion on how we can quantify the benefits stemming from this project for the involved industry and academic partners, beyond the key scientific questions that we can explore with this facility. In the past years, together with collaborators from other universities and research institutes we have tried to identify the key returns for society from public investments in large-scale projects like LHC and its high-luminosity upgrade (HL-LHC) and use these results to forecast the impact of the planned FCCs. These results have been published in a number of papers and I will briefly discuss them below. But let me add, that this exercise also revealed the need for new thinking from scientists, economists and policy makers which is what motivated us to organize this workshop.

\section{Measuring the Socio-Economic Impact: Challenges and Prospects}

In the following few paragraphs, I would like to share some of the insights that we have gained in the past years through our work for the FCC study and the supporting H2020 projects EuroCirCol and EASITrain. The FCC study was launched in 2014 to prepare the ground for a post-LHC research infrastructure and push R\&D lines for technologies that could guarantee a sustainable and cost-efficient construction and operation. After 5-years, the project succeeded in building an international collaboration with more than 150 institutes from around the globe and delivered a fourvolume Conceptual Design Report ${ }^{1}$ that describes in detail some of the topics that I will highlight here.

The socio-economic impact assessment of the LHC/HL-LHC programme, carried out in the scope of an European Investment Bank (EIB) project by the University of Milano (Italy), has revealed the added value of public investment in research infrastructures. This was the first application of this method and gave us some encouraging results to reflect on how this impact can be better measured but also on the tools that would allow to further maximize it. Today, the H2020

\footnotetext{
${ }^{1}$ Future Circular Collider, Conceptual Design Report Volume 2, The European Physical Journal Special Topics, Volume 228, pages 755-1107(2019).

Future Circular Collider Conceptual Design Report Volume 3, The European Physical Journal Special Topics volume 228, pages 261-623(2019).

All the volumes of the FCC CDR can be accessed online here: https://cern.ch/fcc-cdr
} 
EuroCirCol project is a reference case to apply the EU recommended framework for infrastructure CBA to the research community.

Findings of this analysis suggest that training is the single most important generator of socio-economic impact from such endeavours. Let me give an example that stresses the value of training in the different fields linked to the construction, operation and maintenance of an RI. The average salary premium of students involved in a large-scale particle accelerator research project across sectors and domains is between $5 \%$ and $13 \%$ in addition to the premium of obtaining a higher-education level academic degree (Master or doctoral degree). A conservative approach to translate this into an absolute monetary value yields a life-time (we estimated 40 years of professional active period) added premium of 150,000 Euros on average per student or early stage researcher.

In addition, this work identified the possible lack of a new generation of welltrained lead engineers in the domains of superconductivity and cryogenics. Maintaining a pool of skilled engineers and scientists in these fields is crucial not only for high-energy physics but for the more than 50,000 accelerators that operate worldwide from the pharmaceutical and food industry to global transportations and medical treatment. Consequently, the FCC project consortium submitted the EASI TRain (European Advanced Superconductivity and Innovation Training Network) proposal for a MSCA training network that was accepted in 2017. The project will continue running until June 2021, training a new generation of experts and leaders in the while establishing a curriculum that will serve as roadmap for future training \& education in these fields. Moreover, many of the early stage researchers will pursue careers in other fields, outside particle physics, thanks to the skills that they will acquire during the EASITran and the network that they develop in the course of this project.

Beyond training, there is also a dominant effect from public investment in such facilities for the industry as also demonstrated by some of the previous speakers. Industries profit most via co-innovation and co-development in the mid- to hi-tech sector and for cutting-edge technologies that are brought to maturity. Big science centres like CERN are highly complex collections of instruments and installations, and invest heavily in the development of specifications of highly advanced technologies. They carry out large-scale construction projects according to strict plans and shared objectives, which are passed on to industrial suppliers in technical specifications as part of procurement procedures. Innovation and knowledge spillover between big science centres and industry is a process of interactive learning in a mutual relationship based on the complementary resources and objectives of the two organisations as previously shown ${ }^{2}$.

Last but not least, an interesting finding from this work is the high value of cultural goods (science tourism, books, films, exhibitions) stemming from such large-scale facilities. Cultural effects, while uncertain because they depend on future announcements of discoveries and communication strategies, were estimated to

\footnotetext{
${ }^{2}$ Autio, E., Hameri, A.-P., \& Vuola, O. (2004). A framework of industrial knowledge spillovers in big-science centers. Research Policy, 33(1), 107-126.
} 
contribute $13 \%$ to the total HL-LHC benefits. More than half of this percentage comes from onsite visitors to CERN and its travelling exhibitions. Science is a global affair, but of course the love about science and the public appreciation remains bound to regional factors that should be further understood and explored. The cultural goods stemming from Big Science can also be a ground for synergies with other existing or planned RIs. Here one should also mention the willingness of taxpayers to support such a research infrastructure with comparable high amounts per year (order of 4 Euro/year/person) though the study revealed a strong correlation of the willingness to pay with the educational level of the citizens as well as their knowledge about the goals and scope of the planned infrastructure. This bring me to the last point of my talk about the value of communicating our work and engaging with the public throughout the lifetime of a project.

All in all, it is clear that understanding the socio-economic impact of Big Science demands a large-scale institutional response. There is a colourful landscape of impacts that come out from public investments in such facilities long before-and on top-the scientific lessons we gain. The applied methodologies and the interpretation of results should be a major subject in public policy, and at grant agencies and universities. I hope that this workshop and the discussions we have will contribute to this direction.

\section{Future Outlook}

Let me conclude this brief summary by pointing out a few possible avenues for further analysis that have been identified through our previous work in the framework of the HL-LHC project and the FCC study. As it is often the case in scientific inquiry, trying to answer one question generates more. However, I think that these points could help in shaping a common agenda for other RIs managers and policy makers and enable collaborations between different scientific projects:

- Analyse the wider social returns to non-R\&D intangible investment. Evidence to date has focused largely on spillover returns from public and private $R \& D$ investments. This approach neglects the cultural and educational impact with the training aspect should be further explored and understood. This also calls for innovative approaches like the one presented by Prof. Loureiro and her colleagues using Big Data from social media.

- Further work to understand the wider 'public good' benefits of publicly-funded knowledge investments. Of course, the impacts of public R\&D on a high-field magnet, a novel acceleration technology or a superconductor are extremely difficult to measure, but further attempts to do so would be useful and add significantly to the evidence base on the returns to knowledge investments. We also understand that it is hard to quantify the impact of inventions like the WWW but there are similar other developments where HEP is significantly involved 
(i.e. detector technologies, computing, material science) and these contributions should be quantified. ${ }^{3}$

- Evidence on how firms in non-R\&D intensive industries innovate and draw on public investments to do so through joint activities with Research Infrastructures. ${ }^{4,5}$ The exposure to an international environment, the impact on a company's brand name are among the additional impacts coming through joint activities with a big research infrastructure. ${ }^{6}$

- The regional and global impact of the existence of a big Research Infrastructure in non-R\&D intensive industries. Sectors like retail, financial services, transport and utilities represent large parts of the economy, and profit in different ways from the existence of a research facility in a specific area.

- Clearer evidence on the impacts of interaction between different forms of knowledge investments, not least the impact on returns, would be helpful. ${ }^{7}$ It is never easy to isolate linear cause-effect 'returns' on research investment, but more granular evidence on these synergies and complementarities can always help.. This should include a combination of detailed data analysis of how R\&D investments on new technologies spread across the whole value chain of a product and/or among different industries, and case study evidence.

- Given the emergence of different approaches for assessing the societal impact of RIs in different countries, and that by nature knowledge investments are highly internationally mobile, it would seem important that there is an attempt to coordinate across countries the collection and analysis of data. This is already the goal of the H2020 RI-Paths project, as presented by A. Reid. This CSA action is currently ongoing and will help coming to a more homogeneous framework for impact assessment, needed for the next phase of the development of a particle collider-based research infrastructure

It is generally agreed that the realization of a new research facility is both a technological and a social process; the interests and expectations of the different participating actors show up in its design. This means that the economic and social impacts should no longer be generated by accident, in an episodic fashion but rather be inclusively identified and shaped, and then well integrated from the very start of the design process. This requires a new best-practice box of management tools, risk

\footnotetext{
${ }^{3}$ Abreu, M., Grinevich, V., Hughes, A., and Kitson, M. (2009), Knowledge exchange between academics and the business, public and third sectors, UK Innovation Research Centre, University of Cambridge and Imperial College London (http://www.cbr.cam.ac.uk/pdf/AcademicSurveyReport. pdf)

${ }^{4}$ Czarnitzki, D. and Thorwarth, S. (2012), "Productivity effects of basic research in low-tech and high-tech industries", Research Policy, 41(9), 1555-64

${ }^{5}$ González, X. and Pazó, C. (2008), "Do public subsidies stimulate private R\&D spending?", Research Policy, 37(3), 371-389.

${ }^{6}$ Impact of CERN procurement actions on industry: 28 illustrative success stories, Centre for Industrial Studies, Milan (2018): https://cds.cern.ch/record/2670056

${ }^{7}$ Park, W.G. (1995), "International R\&D Spillovers and OECD Economic Growth", Economic Inquiry, 33(4), 571-91.
} 
analysis, administrative resources and strategy tuned to the size of the projects. Much as we devise new scientific instruments in relation to the precision we are aiming to achieve and the particle we want to study. Time will tell how these considerations can be applied to future research infrastructures and help increase their societal return. I hope that this workshop will motivate further interdisciplinary work to address these pressing questions.

Open Access This chapter is licensed under the terms of the Creative Commons Attribution 4.0 International License (http://creativecommons.org/licenses/by/4.0/), which permits use, sharing, adaptation, distribution and reproduction in any medium or format, as long as you give appropriate credit to the original author(s) and the source, provide a link to the Creative Commons licence and indicate if changes were made.

The images or other third party material in this chapter are included in the chapter's Creative Commons licence, unless indicated otherwise in a credit line to the material. If material is not included in the chapter's Creative Commons licence and your intended use is not permitted by statutory regulation or exceeds the permitted use, you will need to obtain permission directly from the copyright holder. 